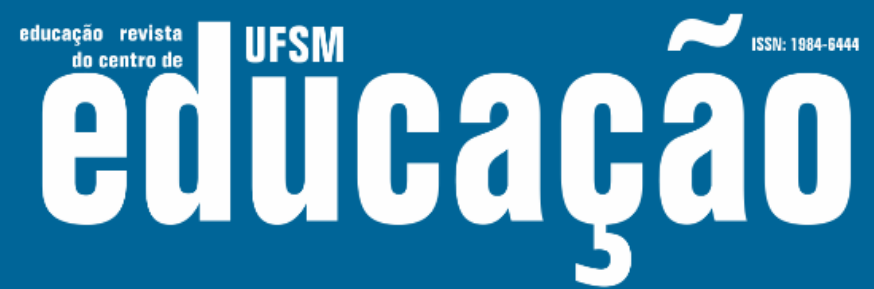

ISSN: 1984-6444 | http://dx.doi.org/10.5902/1984644435065

\section{Processo educativo e personalidade: cuidado e superação do sofrimento psicológico.}

\author{
Education process and personality: attention and overcoming of \\ psychological suffering.
}

\begin{abstract}
* Armando Marino Filho
Professor doutor na Universidade Federal de Mato Grosso do Sul, Três Lagoas, Mato Grosso do Sul, Brasil. armandomarinof4@gmail.com - http://orcid.org/0000-0002-5212-3972
\end{abstract}

Recebido em 05 de outubro de 2018

Aprovado em 12 de junho de 2019

Publicado em 11 de setembro de 2019

\section{RESUMO}

Este artigo objetiva tratar das consequências do processo educativo na formação da personalidade dos indivíduos; resulta de revisão bibliográfica e da prática do autor em ensino e psicoterapia fundamentada na Psicologia Histórico-Cultural; responde à necessidade dos educadores considerarem a afetividade como condição essencial para os processos cognitivos e formação do ser social; toma como eixo do processo educativo a significação social e o sentido pessoal; sugere que as contradições na formação da personalidade podem se transformar em sofrimento e conflito psicológico por meio de uma ruptura entre significado social e sentido pessoal. Os resultados apontam que, os sujeitos podem alcançar, também por meio da educação, o domínio dos meios de orientação e controle de suas relações, superando as contradições que o levam ao sofrimento psicológico durante o processo educativo. Conclui-se, portanto, que a educação tem um duplo caráter humanizador da personalidade, pode tanto causar sofrimento como empoderamento nos sujeitos para superação das contradições geradoras de conflito psicológico.

Palavras-chave: Educação; Psicologia Histórico-Cultural; Sofrimento Psicológico.

\section{ABSTRACT}

This paper seeks to talk about the consequences of the education in the personality development. It stems from a literary review and by the author's practice in teaching and psychotherapy based on Historical-Cultural Psychology. It responds to the need of educators to consider affectivity as an essential condition for the cognitive processes and development of the social being. It assumes the social signification and the 


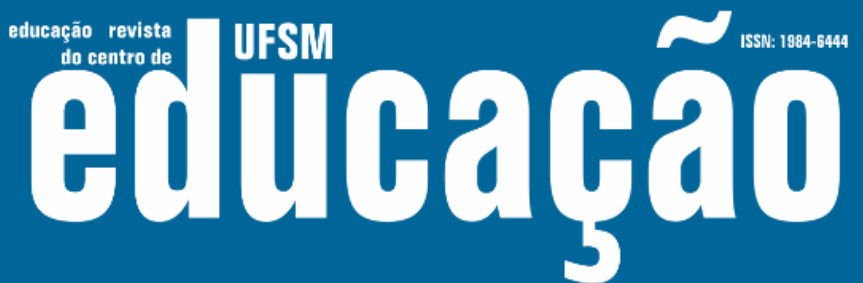

ISSN: 1984-6444 | http://dx.doi.org/10.5902/1984644435065

personal meanings as the center of the education process. It suggests that the contradictions in the personality development can turn into suffering and psychological conflict by a breakdown between social signification and personal meaning. The results show that the subjects can master the means of orientation and control of their relationship to overcome the contradictions that lead to psychological suffering through the educational process. It was concluded, therefore, that education has dual characteristics of personality humanization, as it can cause both pain and empowerment as subjects for overcoming of contradictions that generate psychological conflict.

Keywords: Education; Historical-Cultural Psychology; Psychological suffering.

\section{Introdução}

Uma avaliação do sofrimento psicológico no desenvolvimento social dos indivíduos vem ao encontro das necessidades de desenvolvimento das práticas educativas. A expressão "sofrimento psicológico" é compreendida conceitualmente neste trabalho como a vivência de uma situação/contexto no qual um indivíduo ao enfrentar contradições afetivamente relevantes para a sua atividade vital, se percebe incapaz para a sua superação e age motora e intelectualmente para negar, eliminar, transformar, contornar, as contradições permanecendo por tempo indeterminado e sem êxito nessa situação.

Nesse sentido, é notório que as condições afetivo/emocionais ocupam lugar importante no processo de aprendizagem e formação da personalidade do estudante. A violência no processo educativo, por outro lado, tanto informal quanto formal tem sido preocupação de vários pesquisadores como, por exemplo, Matusov E. \& Miyazaki K. (2014); Sullivan P. (2014); Sposito M. P. (2001); Pino A. (2007). Esses autores apontam para diferentes circunstâncias e condições da existência da violência no processo educativo. Aqui consideraremos principalmente a educação no ambiente escolar, fundamentando a argumentação na Psicologia Histórico-Cultural (PHC), principalmente pelos pressupostos teóricos elaborados por L. S. Vigostki 1996; 2000; 2001; 2001a; 2001b; A. N. Leontiev (1978; 1978a; 1998) e A R. Luria (1998), por meio da qual é possível alcançar uma compreensão do sofrimento no processo educativo e suas implicações para o desenvolvimento psicológico. 


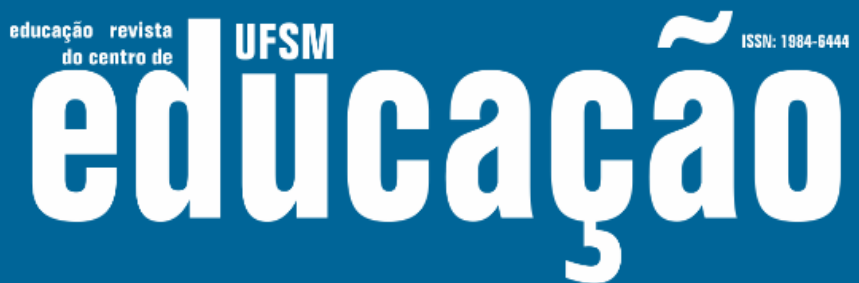

ISSN: 1984-6444 | http://dx.doi.org/10.5902/1984644435065

Primeiro, consideramos que o confronto dos pressupostos teórico/filosóficos e científicos da PHC com outras teorias revela a necessidade de superação de compreensões subjetivistas e naturalizantes do sistema psicológico, da personalidade e do sofrimento como "adoecimento" de fundo biológico, do trabalho educativo como uma relação direta de um agente (professor) sobre o outro (estudante, aluno). Também, de superação da noção de cura e a necessidade de incluir o caráter de desenvolvimento social da pessoa, sujeito do processo educativo. Não por isso, pretende-se excluir o caráter biológico da existência humana, transformando o homem em um ser "puramente" simbólico. O que se faz necessária é a clara explicitação do seu ser como unidade de múltiplas determinações históricas.

Posto dessa forma, portanto, surge para nós a necessidade de proposições que avancem na compreensão do que seja o psiquismo e os processos de intervenção para o seu desenvolvimento e transformação. Avançar, nesse sentido, significa a superação do tecnicismo dado pelos instrumentos, testes, dispositivos de classificação descritiva de diagnóstico e intervenção postos no ambiente escolar pela psicologia e neurologia, por exemplo. Esses, tratam de um sujeito abstrato, generalizado a partir de conhecimentos particularmente biologicistas ou espiritualistas e que excluem o seu ser social, a sua particularidade e as condições de produção da sua existência.

A importância de promover esse debate sobre o processo educativo, a partir da compreensão proposta na $\mathrm{PHC}$, decorre do fato de que isso pode não só contribuir para o avanço nessa área, mas, principalmente, e devido à compreensão que tem do ser humano, dar novos rumos ao atendimento das necessidades concretas gestadas na prática social e que geram sofrimento psicológico. As análises feitas aqui decorrem de estudos fundamentados na metodologia da revisão bibliográfica e do trabalho desenvolvido em orientações de pesquisa, coordenação de estágios em psicologia escolar, baseados no método do materialismo histórico e dialético que fundamenta a PHC e tem o objetivo de contribuir para a construção de proposições metodológicas que avancem no aprofundamento teórico/prático nessa área de atuação e que atendam às especificidades lógicas da PHC. Isso se faz necessário para promover práticas condizentes com os princípios éticos de desenvolvimento humano proposto 


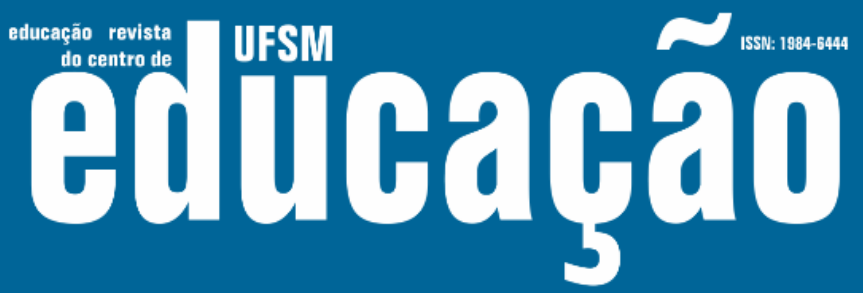

ISSN: 1984-6444 | http://dx.doi.org/10.5902/1984644435065

pela teoria e que evidenciam a gênese social do sofrimento, e orientar a prática à superação das contradições sociais a ele correlacionadas.

\section{Trabalho educativo e formação da personalidade}

O desenvolvimento das capacidades de orientação psicológica para atuação individual e superação das problemáticas postas pelas circunstâncias da vida social, constituem-se em meio essencial para o processo educativo fundado na comunicação e na atividade. Por isso, o trabalho educativo, com base na PHC voltado para os cuidados - ações orientadas intencionalmente e com propósitos humanizadores - com a personalidade, considera-a como síntese das múltiplas determinações sociais que culminam na formação de modos particulares de agir com os objetos, situações e relações com outras pessoas, "[...] a personalidade é uma qualidade especial que o indivíduo natural adquire no sistema de relações sociais" (LEONTIEV, 1978, p. 16).

Uma condição essencial do desenvolvimento da personalidade é a historicidade dos fenômenos humanos. Tomamos, por isso, o fato de que qualquer desenvolvimento depende do conjunto de relações e atividades que um sujeito em particular tem na sua trajetória de vida social, na sua relação com os outros homens. As suas características e peculiaridades advêm dessas relações.

O modo particular de agir deriva das significações sociais que orientam as ações, e se apresenta como reflexo dos sentidos pessoais formados no processo educativo, nas vivências das práticas sociais nas quais os afetos adquirem qualidade e unidade semântica única para cada indivíduo. Compreendemos o sentido pessoal como a forma e a qualidade da relação com um dado objeto, que são mediadas pelo valor ontogeneticamente atribuído a esses objetos e relações na história social particular do sujeito. Segundo Vigotski (2001a) a análise do pensamento, por exemplo,

[...] Revela a existência de um sistema semântico dinâmico, representado pela unidade dos processos afetivos e intelectuais. Mostra como qualquer ideia encerra, transformada, a atitude afetiva do indivíduo para com a realidade representada nessa ideia. Permite também descobrir o movimento 


\section{工 Allbapal}

ISSN: 1984-6444 | http://dx.doi.org/10.5902/1984644435065

direcional que parte das necessidades ou impulsos do indivíduo para uma determinada intenção de seu pensamento e o movimento inverso que parte da dinâmica do pensamento para a dinâmica do comportamento e a atividade concreta da personalidade (VIGOTSKI, 2001a, p. 25, tradução nossa).

Desse ponto de vista, não se trata de trabalhar com descrições classificatórias ou tipológicas da personalidade, mas do reconhecimento da sua ontogenia e historicidade. Trata-se de trabalhar com histórias particulares que não se repetem, e não podem, portanto, ser enquadradas em estruturas previamente determinadas em contextos teóricos. Da mesma forma, as sínteses afetivas que se expressam na personalidade a partir de princípios gerais do desenvolvimento social dos indivíduos, não cabem em quadros de previsibilidade.

Partindo da compreensão na qual a atividade humana é fundada na comunicação e transformação prática da realidade para a manutenção da vida fundamento basilar da humanização -, compreende-se que o homem se constitui nessas relações e, portanto, a estrutura geral do processo educativo se caracteriza como processo de inter-relações ativas e transformadoras entre os sujeitos, que têm implicações afetivo/emocionais para a personalidade. De acordo com Leontiev (1978)

[...] as propriedades psíquicas do homem, tanto gerais como especializadas, não representam a manifestação de algumas propriedades particulares postas biologicamente nele, de que se não poderia constatar senão a presença ou a ausência, mas que elas se formam durante o processo de desenvolvimento e de educação (LEONTIEV, 1978, p. 200).

Nesta significativa afirmação do seu pensamento Marx (2004, p. 110) apresenta essa ideia geral: "[...] não só os cinco sentidos, mas também os assim chamados sentidos espirituais, os sentidos práticos (vontade, amor, etc.), numa palavra o sentido humano, a humanidade dos sentidos, vem a ser primeiramente pela existência do seu objeto, pela natureza humanizada."

Essa forma de compreensão do fenômeno humano é um dos princípios que permite compreender o sistema psicológico como sendo fundado na estrutura da atividade e no processo de significação que formam a personalidade. As análises realizadas por esse princípio viabilizam conhecer a história do sujeito pela sua inserção em atividades sociais, a significação desenvolvida em sua particularidade e os sentidos pessoais que organizam as suas ações em relações conflituosas e 


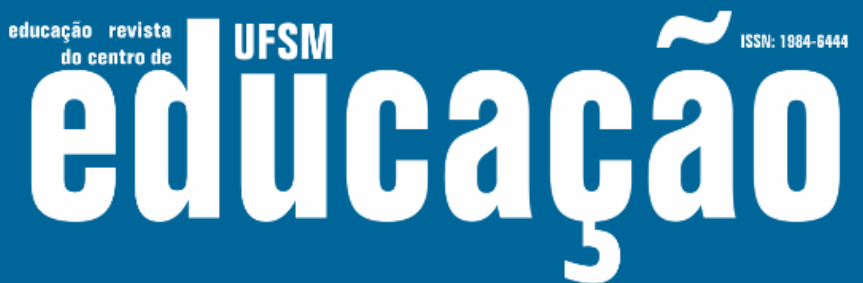

ISSN: 1984-6444 | http://dx.doi.org/10.5902/1984644435065

geradoras de sofrimento psicológico. Acentuamos o fato de que nas relações em que aparece o conflito, aparece na mesma medida a tentativa de exclusão dos elementos que foram estranhados em função de suas divergências.

A significação, isto é, a atividade transformadora dos sinais percebidos pelos órgãos dos sentidos na sua forma natural em signos, em sinais artificiais e significados sociais, segundo L. Vigotski (2001), representa a formação ideal das relações dos homens entre si e com o seu mundo objetivo. Por isso, o significado que resulta da atividade de significação é a forma específica de relação com os objetos e outros sujeitos sociais, criada pelos homens e representada por um signo. A significação é o componente central para a compreensão do desenvolvimento psicológico e de suas particularidades. É, assim, representada pela complexidade da atividade social na qual um indivíduo é incluído como sujeito e resulta, para ele, em sentido pessoal de orientação, execução e controle da sua atividade vital.

Note-se que a significação resulta de uma atividade social, portanto, da interrelação entre os indivíduos e o seu mundo, o mundo da natureza e o mundo humanizado. É um processo que se desenvolve na relação eu/outro em determinadas condições de atividade diádica, ou grupal, ou coletiva e, além do mais, individual em processos reflexivos pelo pensamento, como unidade da sua multideterminação.

O processo de inclusão dos sujeitos em atividades sociais de significação é o meio pelo qual o seu ser biológico advém sociocultural. É um processo educativo. Isso quer dizer que os modos de agir e expressar do ser biológico são transformados em outros modos de ser não exclusivamente naturais, mas históricos.

A estrutura, isto é, a forma que se repete como produto dessa atividade é constituída por signo, significado e sentido pessoal. Quero destacar a ideia de sentido considerando o fato de que o sistema psíquico é fundamentalmente um sistema de orientação da atividade, além da execução e controle. Podemos utilizar como exemplo a palavra como instrumento psicológico quando Vigotski (2000, p. 150) afirma que "[...] A palavra deve possuir, antes de tudo, um sentido, isto é, deve relacionar-se com o objeto; há de existir um nexo objetivo entre a palavra e aquilo que ela significa". Acrescente-se a isso que "[...] Nos primeiros estágios, as palavras designam um 


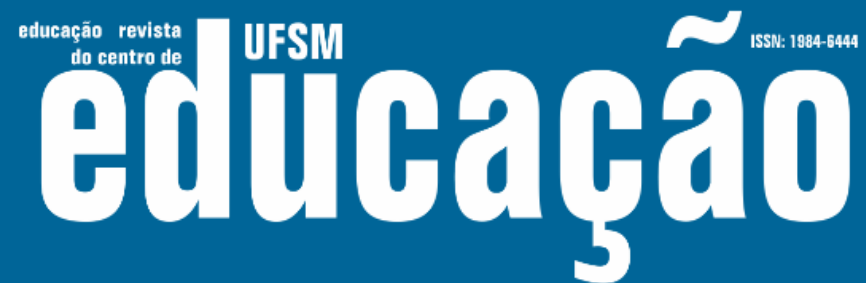

ISSN: 1984-6444 | http://dx.doi.org/10.5902/1984644435065

complexo total de referentes, incluindo não apenas o objeto nomeado mas também os sentimentos da criança em face do objeto" (LURIA, 1998 p. 31).

A orientação da atividade é organizada como sendo social e pessoal ao mesmo tempo, por meio da aquisição da linguagem. Nessa, a unidade subjetividade/objetividade é marcada pela fusão das formas do ser social, que implicam em uma orientação cultural para as atividades, e das formas do ser pessoal que resultam da síntese das vivências afetivo/emocionais. A personalidade se expressa como síntese dessas vivências na sua relação cognitiva com o mundo. Todo ato de conhecer está direto ou indiretamente relacionado com as necessidades da pessoa em suas vivências. A vivência "[...] deve ser entendida como a relação da criança como ser humano, com um ou outro momento da realidade. Toda vivência é vivência de algo. Não há vivencia sem motivo, como não há ato consciente que não fora ato de consciência de algo. Não obstante, cada vivência é pessoal” (VIGOTSKI, 1996, pg. 383, grifo nosso, tradução nossa).

As necessidades do indivíduo como personalidade são produzidas pela prática social. Volto chamar a atenção para a proposição de Karl Marx (1977) na qual demonstra o fato histórico do surgimento de novas necessidades, ou da humanização das necessidades naturais na atividade social. A necessidade como carência biológica, desenvolvida no processo evolutivo de hominização, como carência do metabolismo material - no âmbito da natureza - é transformada na atividade social caracterizando-se como produto dessa nova forma de relação dos homens entre si. Mais ainda, transforma-se igualmente em objeto para os sujeitos. Assim o autor afirma que,

[...] para viver, é necessário antes de mais beber, comer, ter um teto onde se abrigar, vestir-se, etc. O primeiro fato histórico aponta a produção dos meios que permitem satisfazer as necessidades, a produção da própria vida material. O segundo ponto a considerar é que uma vez satisfeita a primeira necessidade, a ação de satisfazê-la e o instrumento utilizado para tal conduzem a novas necessidades [...] (MARX, 1977 p. 39-40).

Por que as novas necessidades, ou as necessidades humanizadas, se transformam em objeto para os sujeitos? Quais são as implicações para a sua 


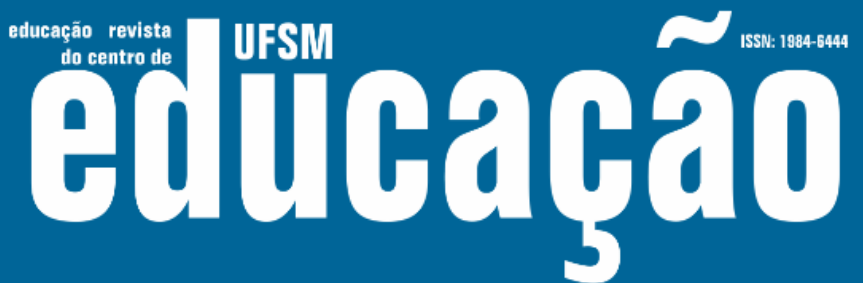

ISSN: 1984-6444 | http://dx.doi.org/10.5902/1984644435065

formação psicológica e para o processo educativo? Qual é a relação que esse fato tem com o sofrimento psicológico?

Para considerar essas questões é preciso perceber que de fato os indivíduos são postos em atividades sociais nas quais as diferentes formas de uso de instrumentos, conhecimentos, formas de pensar, agir, etc. não são, a princípio, necessidades suas. No entanto, a participação, o pertencimento ao grupo social e todas as condições da atividade que garantem a manutenção da vida individual indicam para o domínio dos meios e relações como condição para a transformação de si em sujeito social. O uso e domínio dos objetos culturais se transformam, por isso, em necessidades pessoais, em objetos e motivos.

Ocorre, assim, um processo de transformação das formas de existir, e o surgimento de um tipo totalmente novo de atividade. A atividade social radicalmente distinta da biológica. A base biológica natural da atividade vital não pode ser excluída da existência dos indivíduos e é, ao mesmo tempo, insuficiente para caracterizar a forma humana da atividade. É para além dessa base que surge o novo como necessidade, e a própria necessidade como objeto de reflexão, como consideração afetivo/emocional das diferentes posições que o sujeito ocupa nas relações sociais. Nesse sentido, ocorre o desenvolvimento da consciência como expressão do conhecimento da realidade e de si ao mesmo tempo. Vigotski (1996) explica que

[...] a criança se exclui do mundo circundante, elabora gradualmente uma nova relação com o meio ao longo de diversos estágios, qualitativamente distintos uns dos outros, no desenvolvimento da consciência de sua personalidade e de sua unidade, por uma parte, e no desenvolvimento da consciência da realidade e sua unidade, por outra. Chamamos a essas duas sínteses que surgem no pensamento da criança: personalidade e concepção de mundo. (VIGOTSKI, 1996, p. 280, tradução nossa, grifo nosso)

Quero apontar, partindo do que foi grifado na citação acima, que o sujeito elabora, isto é, trabalha no processo da transformação particular dos sentidos que as relações sociais apresentam em forma de afetação e conhecimento. É nesse sentido que o sujeito não é uma cópia das relações sociais, mas nela se individualiza. É, por isso, ativo na produção das suas formas particulares de agir, pensar e sentir, de si como personalidade. 


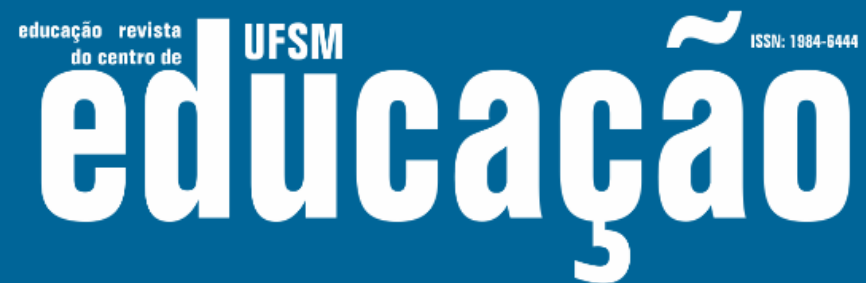

ISSN: 1984-6444 | http://dx.doi.org/10.5902/1984644435065

O fato de que seja ativo não quer dizer que esses processos ocorreram de forma isolada e espontaneísta. As implicações para a formação psicológica e educacional da criança abandonada a aprender a desenvolver-se por si mesma, por exemplo, resultam em deformação no desenvolvimento da personalidade e da concepção de mundo. É por isso que a educação é uma atividade de estreito acompanhamento das sínteses afetivo/emocionais e cognitivas que a criança elabora sobre si e o mundo. É por isso que, também, a mediação não se restringe à organização ou apresentação dos conteúdos de ensino, mas como profundo envolvimento do educador no processo de humanização integral do sujeito, isto é, sobre todas as formas de existência do seu sistema psicológico. Nesse sentido, adotamos, ainda, o sentido amplo do conceito de educação na mesma medida dada por I. Mészàros (2005) quando afirma que,

Em outras palavras, no sentido verdadeiramente amplo do termo educação, trata-se de uma questão de "internalização" pelos indivíduos [...] da legitimidade da posição que Ihes foi atribuída na hierarquia social, juntamente com suas expectativas "adequadas" e as formas de conduta "certas", mais ou menos explicitamente estipuladas nesse terreno (MÉSZÀROS, 2005, p. 44).

O sistema psicológico pode ser compreendido como um sistema de orientação, execução e controle da atividade viva, que é mediada por processos cognitivos e afetivo/emocionais resultantes da atividade orgânica que é transformada em meio social e adquire formas de existência culturalmente significadas e internalizadas pelos indivíduos. O sistema psicológico, portanto, é entendido como uma qualidade nova de orientação que surge dos processos educativos.

O nosso foco recai justamente sobre o fato de que esse novo sistema, que advém de configurações historicamente desenvolvidas e já existentes antes da inserção do indivíduo como sujeito social, se dá forçosamente de forma contraditória. Os modos de agir imediatamente próprios do indivíduo singular, que podemos denominar de naturais são negados, contraditoriamente pelos socioculturais. A negação aqui tem o sentido não de exclusão, mas de negação por incorporação, isto é, a sua subsunção a outra forma de existência diferente. A. N. Leontiev (1978) tratando do processo de aprendizagem e apropriação pela mediação do adulto e a formação de ações pelo "meio circundante", afirma que essas condições, 


\section{工 urs N N

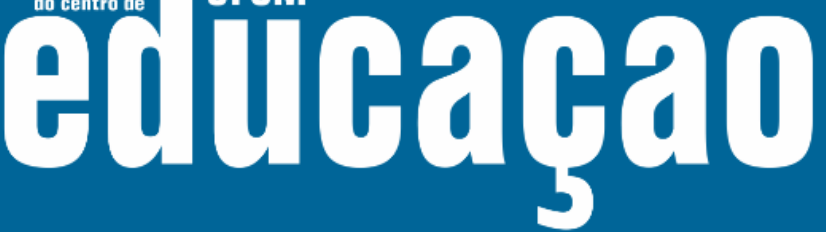

ISSN: 1984-6444 | http://dx.doi.org/10.5902/1984644435065

[...] à força de se repetir, elas elaboram-se na criança e adquirem a propriedade de se adaptar às modificações mesmo profundas das condições concretas. Este processo de adaptação das ações realiza-se já segundo mecanismos gerais de formação da experiência individual, mas agora estes mecanismos asseguram a adaptação à variação das condições concretas de ações historicamente elaboradas assimiladas pela criança, e não as variações das condições concretas do comportamento hereditário específico, como é o caso no animal (LEONTIEV, 1978, p. 187).

A superação da mera adaptação à natureza na gênese do comportamento, isto é, das formas de comportamento derivadas da adaptação passiva diante das forças da natureza, adquire uma nova forma com o desenvolvimento histórico-social. Notese que o homem exerce agora o papel ativo de adaptação do seu mundo, não somente das forças da natureza, mas também das suas relações com seus semelhantes às suas necessidades. Da mesma forma, organiza-se um ajuste das suas formas de agir diante dessa transformação que ele mesmo produz. A isso se pode denominar de auto atividade criadora de formas particulares de lidar com o mundo. Sendo assim, a atividade criadora de formas particulares de ação significa que o "[...] $\bigcirc$ fato psicológico decisivo consiste no deslocamento dos motivos de uma ação para os fins que precisamente não respondem diretamente às necessidades biológicas naturais" (LEONTIEV, 1978, p. 108).

Nesse sentido, da alteração dos motivos, uma questão importante a ser considerada é o processo afetivo. Tomaremos a afetação como o processo pelo qual o homem entra em contato com o mundo por meio da sensibilidade e sensações. Por meio dos órgãos dos sentidos, o organismo sofre uma irritação do sistema nervoso pelas qualidades físicas e materiais dos objetos, por meio da sensibilidade (LEONTIEV, 1978). Essa relação é registrada no cérebro como um afeto, isto é, como registro da relação do sujeito com os objetos da sua relação que é constituído de um valor que representa os efeitos da relação nos processos biológicos. Estes efeitos têm qualidades que podem ser percebidas como positivas ou não pelo indivíduo.

É por isso que o processo de criação de formas particulares de agir, pensar, sentir e participar da atividade social pode ser pensado como luta, como síntese das contradições presentes nas multideterminações postas pelas atividades sociais de 


\section{Aีtิดaหูão}

ISSN: 1984-6444 | http://dx.doi.org/10.5902/1984644435065

humanização. Luta que não ocorre, como diz Marx (2004) - sem sofrimento - e Vigotski (2000) - sem afetação.

[...] a adaptação não deve ser considerada senão do ponto de vista social. Nesse caso nunca se deve partir de um meio social dado como de algo constante e imutável. O meio social contém uma infinidade dos mais diversos aspectos e elementos. Esses elementos estão sempre na mais violenta contradição e luta entre si, e todo o meio deve ser entendido não como um sistema estatístico, primordial e estável de elementos, mas como um processo dinâmico em desenvolvimento dialético (VIGOTSKI, 2001a p. 278, grifo nosso).

O fato no qual o sujeito toma as suas necessidades como objeto de consideração e que esta reflete o contexto sócio-educativo contraditório e gerador de afetação e sofrimento tem importantes implicações para o processo educativo. Duas questões a considerar se apresentam: o caráter criativo da atividade humana e, como consequência, a possibilidade de desenvolvimento de formas alternativas de comportamento que refletem as tentativas pessoais de superação das contradições postas no processo de sua individuação social.

A inevitável condição de transformação da singularidade biológica em individualidade sócio-histórica por conta da inclusão nas atividades sociais e o também inevitável surgimento da personalidade como resultado das vivências contraditórias na existência grupal, levam à criação pessoal de formas particulares de enfrentamento das contradições. Desde muito cedo a criança demonstra essa condição na sua humanização cotidiana no contexto do seu desenvolvimento. Uma questão importante sobre isso: é preciso evitar o risco de ao identificar essas produções particulares como expressão de estágios ou fases naturais de desenvolvimento, tomá-los como recorrentes, classificáveis, e com isso normatizar o sofrimento.

A possibilidade de variação dos modos, dos conteúdos e da gênese do sofrimento é tão extensa quanto são as histórias particulares. Isso pode ser compreendido como resultado do desenvolvimento da imaginação no processo de significação e aquisição da linguagem. Cabe aqui explicitar que a geração de imagens por meio dos órgãos dos sentidos, da afetação sensível, é um processo fundamental para a formação do sistema psicológico. É um processo inicial, base do registro ideal 


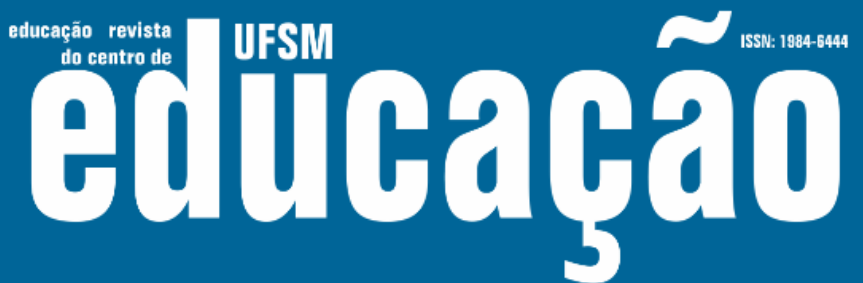

ISSN: 1984-6444 | http://dx.doi.org/10.5902/1984644435065

da relação do indivíduo singular com o seu mundo. Porque registro da relação é também articulação do movimento entre as diversas afetações e o próprio sujeito (ILYENKOV, 2010).

A significação, constituída pela atividade social, é plena das vivências afetivas e de formação de sentido pessoal por um lado, e, por outro, da aquisição de instrumentos-signo que viabilizam o processo criativo por meio da linguagem e seus significados. O caráter instrumental das funções psicológicas complexas é marcado pelo fato de o homem usar objetos auxiliares, produzidos por si mesmo, que vão intermediar suas relações com o mundo (LURIA, 1998). Entendemos que objetos podem ser tanto os materiais quanto os ideacionais, como representações, imagens, significados, sentidos etc.

É de se notar, por isso, que a geração de imagens se enriquece como imaginação com a aquisição de significados sociais e se constitui em atividade intelectual essencial ao sistema psicológico. O processo de simbolização considerado aqui como a possibilidade de articulação de dois ou mais signos na produção de um novo significado - revela toda a gama de possibilidade criativa pessoal de formas particulares de sentidos que organizam a orientação da atividade psicológica. Como aponta Vigotski (1996),

A linguagem libera a criança das impressões imediatas sobre o objeto, the brinda com a possibilidade de representar-se tal qual o objeto que não é visto e pensar nele. Com a ajuda da linguagem, a criança obtém a possibilidade de liberar-se do poder das impressões imediatas, saindo para além dos seus limites (VIGOTSKI, 1996, p. 432)

Quero afirmar que o sofrimento psicológico é uma condição inevitável do processo educativo. Neste a criança vive a contradição da transformação do seu ser biológico em, também, ser cultural. No entanto, as formas culturais de educação que representam também um ato de violência contra a natureza da criança, podem ser alteradas. Por isso, as características do sofrimento psicológico no processo educativo não podem ser naturalizadas. É necessário contextualizá-las cultural e historicamente no modelo político, econômico e ideológico atual que condicionam o processo educativo. 


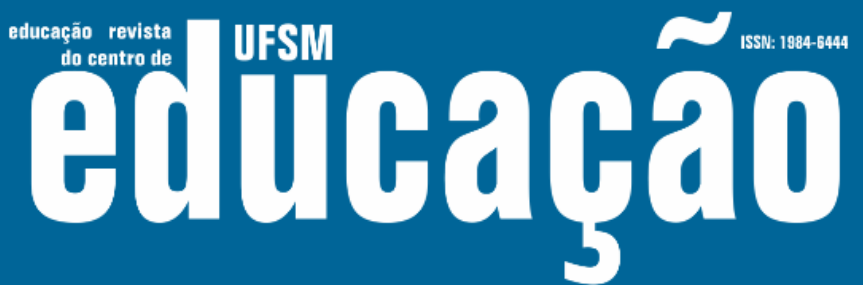

ISSN: 1984-6444 | http://dx.doi.org/10.5902/1984644435065

Vimos, então, que o processo educativo, por força de ser contraditório, afeta e faz desenvolver sentidos psicológicos que entram em conflito nas relações sociais dos sujeitos. Essa é a condição na qual se estrutura a personalidade e o sofrimento psicológico. Faremos, agora, uma apreciação do seu contrário, isto é, da própria atividade educativa como meio de superação dos problemas que causa.

\section{Educação e o possível cuidado com a formação da personalidade}

Considerando o que foi afirmado no tópico anterior cumpre ponderar, então, a educação como atividade que extrapola o caráter de processo estritamente cognitivo e abarca a unidade complexa do psiquismo humano. Assim é porque o processo educativo não é possível sem afetação e esta, por sua vez, é a base da valoração pessoal das relações que o sujeito estabelece com o seu mundo. $O$ valor afetivo constitui o sentido pessoal e uma parte da orientação das ações que se funde com o sentido e valor social da atividade, é no conflito entre esses dois sentidos que se expressa o sofrimento e é, portanto, na sua superação que encontra, também, a possibilidade de cuidados, isto é, ações orientadas intencionalmente e com propósitos humanizadores, como dito acima, à formação da personalidade.

Por meio da educação tanto se formam modos de ser que convergem para as necessidades sociais de produção da vida, da sociabilidade e de relações comunitárias como os modos de produção de necessidades para uma vida individualizada, conflituosa e, também harmoniosa com a comunidade e com a sociedade. Por isso, há possibilidades de uma educação efetiva para a formação da personalidade por meio do cuidado na orientação e intencionalidade com os objetivos educacionais e o cuidado de reconstituição no processo de significação da unidade dos significados sociais e sentidos pessoais.

De forma geral o cuidado no processo educacional se volta para a produção de processos ativos e inter-relacionais, nos quais os sujeitos vivenciam atividades significativas que thes permitem alterar os sentidos pessoais das relações conflituosas. Isso ocorre por meio da inclusão de novos significados e sentidos pessoais no sistema de significação que envolve particularidade dos sujeitos. A 


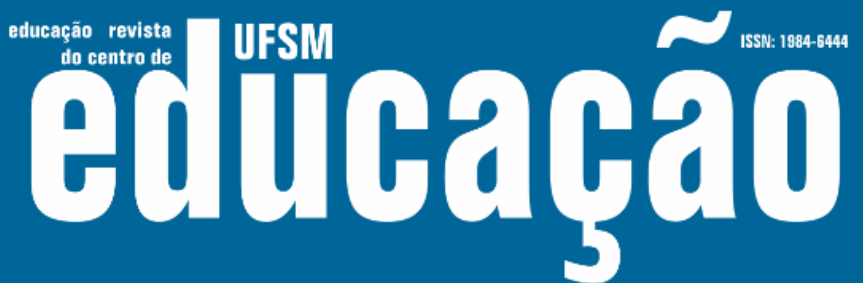

ISSN: 1984-6444 | http://dx.doi.org/10.5902/1984644435065

produção de vivências que criam necessidades novas e, portanto, novos objetos/motivos das ações, mediadas pela inter-relação, pelo uso da linguagem enquanto meio de produção de sentidos, leva a alterações nas relações concretas dos sujeitos. Como explica Leontiev (1978a),

O sentido da ação muda quando se modifica o seu motivo. Por seu conteúdo objetivo a ação pode seguir sendo quase a mesma, mas se adquiriu um novo motivo, psicologicamente já é outra. Transcorre de outro modo, se desenvolve de outro modo, conduz a consequências subjetivamente muito distintas, ocupa outro lugar na vida da personalidade (LEONTIEV, 1978a p. 218, tradução nossa).

A inclusão de novos significados altera a relação sistêmica da atividade geradora de sofrimento, possibilitando ao sujeito superá-lo por meio da, também, formação de novos sentidos pessoais. O resultado de pesquisas, realizadas por Vigotski (2001) demonstra que os significados existem em movimento de transformação quando afirma que "Em seu emprego interior, cada palavra vai adquirindo gradualmente outros matizes, outras nuances semânticas, que se transformam em novo significado da palavra na medida em que se vão constituindo e se condensando (Vigotski, 2001 p. 472)."

É desse ponto de vista que se considera, aqui, os cuidados com a personalidade. Trata-se de reconhecer que no mesmo processo se pode produzir relações que alteram, a constituição semântica dos significados, alterando os motivos da personalidade em determinadas relações sociais. O cuidado orienta justamente para a formação da personalidade nas esferas de relações e atividades sociais enquanto o processo de transformação na atividade educativa, que reorganiza 0 processo de significação onde isso for necessário para a superação dos conflitos pessoais.

É fundamentando-se em outro princípio estruturante que é possível compreender essas afirmações acima. Esse princípio refere-se à condição que não se pode eliminar da existência, a contradição, ou a unidade da diversidade. A contradição é compreendida aqui não como a negação formalista, mas como unidade de movimento em qualquer relação na qual seus componentes se negam e se afirmam ao mesmo tempo em que se constituem de forma interdependente. Revela a 


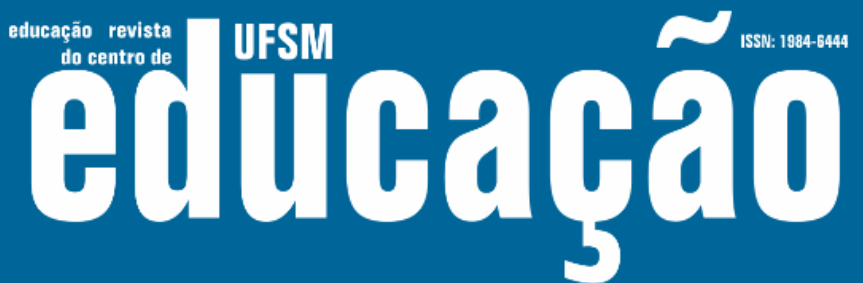

ISSN: 1984-6444 | http://dx.doi.org/10.5902/1984644435065

identidade e a alteridade em unidade e, portanto, o novo que se produz no movimento entre os contrários e que altera as suas formas de existência (WILDE, 1999).

Contrariando o princípio formalista da inexistência da contradição na realidade e que ela somente se manifestaria no pensamento, portanto, causa de erro no julgamento da realidade, a compreensão aqui é radicalmente contrária. Partimos do princípio no qual a realidade é contraditória e o mundo ideal, o pensamento e as possibilidades de avaliação da realidade advêm da relação do homem com as contradições, com aquilo que se torna realidade para ele no processo de significação. As contradições no pensamento resultam da atividade concreta na qual o conhecimento e as afetações adquirem motivos cognoscitivos fundidos aos motivos afetivo/emocionais que constituem a personalidade humana. Como aponta Leontiev,

A via aberta pela análise histórica mostra, [...], que as propriedades do psiquismo humano são determinadas pelas relações reais do homem com o mundo, relações que dependem das condições históricas objetivas da sua vida. São estas relações que criam as particularidades estruturais da consciência humana, e que por ela são refletidas. Assim se caracteriza o psiquismo humano na sua verdadeira essência social (LEONTIEV,1978, p.138).

Atentemos aqui para o fato no qual, na realidade, esses motivos não se excluem no movimento contraditório de sua formação, mas se negam e se afirmam ao mesmo tempo em que se constituem. O conflito no pensamento, no entanto, emerge justamente quando a unidade dos contrários não adquire sentido concreto (subjetivo/objetivo) para o sujeito e são impossíveis de se unificar. É a cisão de sentido e significado, como afirma Leontiev (1978), que aparece como momento de ruptura no sistema psicológico de orientação de alguma relação vital para o indivíduo.

As contradições na formação social da personalidade são compreendidas, assim, na sua dialeticidade. Isto quer dizer que em qualquer contradição os constituintes de uma dada unidade afetiva, de significação e de sentido, por exemplo, são complementares e não excludentes, de modo que a existência de um implica na existência do outro seu constituinte e vice-versa. É nesse sentido que a contradição eu/outro é compreendida na formação social da personalidade, de modo que essa não pode ser considerada como atributo de um indivíduo, mas produto de múltiplas 


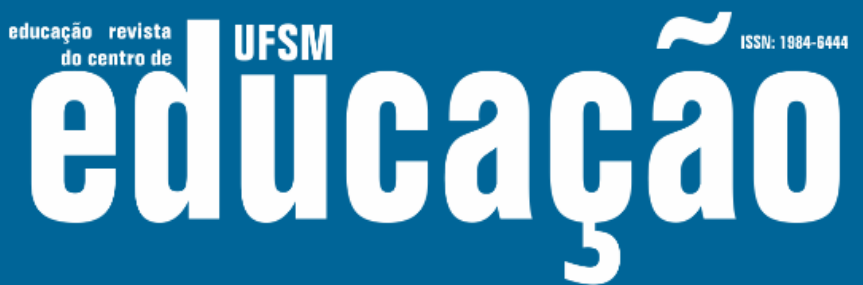

ISSN: 1984-6444 | http://dx.doi.org/10.5902/1984644435065

relações de significação e formação de sentido, que se dão durante as vivências da prática social.

Essa compreensão é importante para a afirmação de que não são as contradições em si que causam o sofrimento psicológico, porque não podem existir em um sujeito como condição a priori, sem relações com outros sujeitos. O sofrimento ocorre quando elas entram em conflito, isto é, quando ocorre o desenvolvimento de uma relação de anulação ou eliminação de uma das unidades que formam a contradição e a sua desarticulação. O conflito se expressa como a destruição das contradições necessárias à formação ou transformação dos fenômenos psicológicos de orientação do sujeito em sua realidade. Por isso, Leontiev (1978, p. 125) quando trata da alienação na sociedade aponta para a "(...) 'desintegração' da sua estrutura [da consciência] que caracteriza o aparecimento de uma relação de alienação entre os sentidos e as significações, no qual o seu mundo e a sua própria vida se refratam para o homem". É nessa condição que surge o estranhamento de si no mundo, do mundo como a negação de si.

O desenvolvimento da personalidade é a alteridade em movimento, em processo de constante transformação dialética. Somente quando pela tentativa de anulação ou destruição das contradições que engendram o movimento das unidades eu/outro, o núcleo do sistema "eu" se cristaliza em formas de existência fixas e reiterativas dessa tentativa $\mathrm{e}$, isso, implica na impossibilidade da transformação e desenvolvimento afetivo, cognitivo e emocional que deveriam acompanhar as relações do sujeito. É assim que se caracteriza o conflito que gera sofrimento. É por isso que, também, os cuidados com a personalidade devem pôr em movimento aquilo que se fixou como modo de relação que não encontra unidade da personalidade com o ser do seu meio social, em determinadas relações. Compreendemos, assim, a possibilidade de a educação exercer efeitos contrários ao sofrimento psicológico e de ajuda na sua superação. 


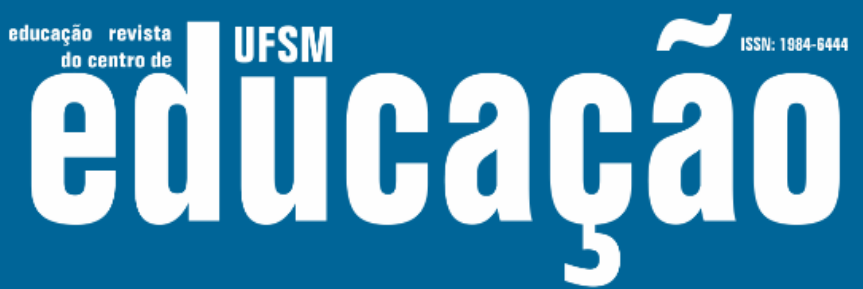

ISSN: 1984-6444 | http://dx.doi.org/10.5902/1984644435065

\section{O papel da educação na superação do sofrimento psicológico}

Compreender que os conflitos se expressam como desintegração da relação entre sentidos pessoais e significados sociais, e que isso altera o sistema de orientação, execução e controle da atividade particular do sujeito no círculo das suas relações sociais, permite-nos uma aproximação às implicações diretas que essa condição tem sobre o poder de domínio das próprias relações. O poder humano se manifesta em forma de ser, agir, pensar e sentir que são produtos de sua própria atividade vital e sociocultural e se forma no processo educativo. A desintegração manifesta sempre em vivências de relações de poder que se caracterizam como conflito no domínio das relações eu/outro, incluído aí tudo aquilo que pertence à relação sujeito/objeto, como pessoas, ideias, sentimentos, etc.

Como as relações e suas contradições ocupam o centro cognitivo e afetivo/emocional da personalidade, é por meio do poder de realizá-las e do domínio das suas condições que o sujeito efetiva a transformação/superação das contradições e condições adversas da sua vida. Cumpre-nos afirmar, portanto, que o papel da educação no cuidado com a personalidade é o de produção de relações (atividades intencionalmente organizadas) que levem a significações e sentidos pessoais que se constituam em formação do poder e domínio sobre as situações de conflito e sofrimento psicológico.

É preciso compreender que a atividade tem uma estrutura geral organizada pela existência de uma condição de necessidade do sujeito que pressupõe, portanto, a existência de um objeto material ou ideacional que é o conteúdo essencial da necessidade. É esse objeto que se transforma em motivo da atividade, e que para alcançá-lo se faz necessário, também, a produção de ações e operações coordenadas (LEONTIEV, 1978).

Quando o sujeito, no entanto, não possui os meios, instrumentos ou recursos ideacionais para operacionalizar as ações, o objeto/objetivo de sua atividade não pode ser alcançado. Essa condição cria uma nova necessidade que por sua vez demanda outra atividade objetivada a conseguir os meios, instrumentos e recursos para 


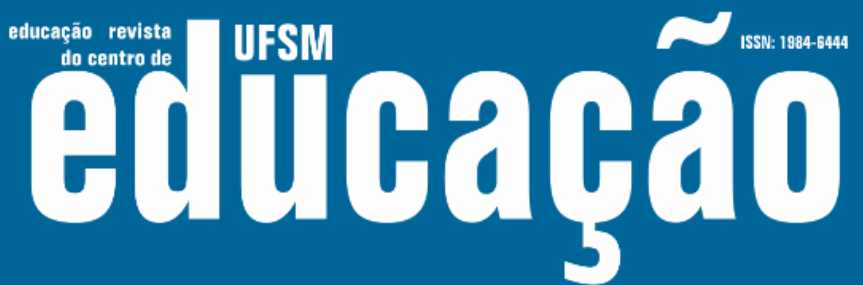

ISSN: 1984-6444 | http://dx.doi.org/10.5902/1984644435065

alcançar o objetivo da primeira ou, diferente disso, voltar-se a outra atividade não diretamente relacionada.

É importante considerar que o fato de que em uma dada atividade se crie necessidades novas, com motivos novos ligados à primeira, torna-se meio para a elaboração de situações e atividades intencionalmente planejadas para a significação de um dado objeto das relações do sujeito. A significação, como atividade, altera os significados e possibilita a apropriação de novos signos. Cria diversidade de motivos que levam à alteração dos sentidos pessoais da atividade. Neste caso ocorre o desenvolvimento do poder e do domínio sobre a própria atividade e, portanto, das possibilidades de superação das contradições.

Essa estrutura e dinâmica da atividade é, assim, representativa da unidade objetividade/subjetividade, sendo, por isso, válida também para o pensamento, para os processos de significação e expressões afetivo/emocionais. As ações do pensamento que se dão por meio dos significados submetem-se à mesma estrutura e organização. Quando o pensamento motivado para o encaminhamento de qualquer relação não encontra os meios necessários (ideacionais) ou é constituído por afetos impeditivos da efetivação das suas ações, o sofrimento também se estabelece como condição. Mas também, o contrário disso é verdadeiro se no processo educativo se cuida de proporcionar ao sujeito a aquisição desses meios. É justamente a aquisição desses meios no processo educativo que formam as funções psicológicas superiores ao domínio da realidade e das possibilidades da sua superação.

Tomamos, por isso, outro princípio fundamental do cuidado no processo educativo, aquilo que Vigotski (2000) denominou de lei geral do desenvolvimento psíquico, que afirma o fato de que o sistema que orienta psicologicamente o indivíduo existe primeiro nas suas relações com outras pessoas e somente depois que essas relações são internalizadas se transformam em modos próprios do indivíduo. É importante salientar que esse caminho, necessariamente, faz parte da atividade educativa. A relação interpsíquica que se transforma em intrapsíquica deve caracterizar o processo. Igualmente, Leontiev (1978a, p. 78) explica que "o processo de interiorização consiste em que a atividade exterior se desloca a um 'plano de 


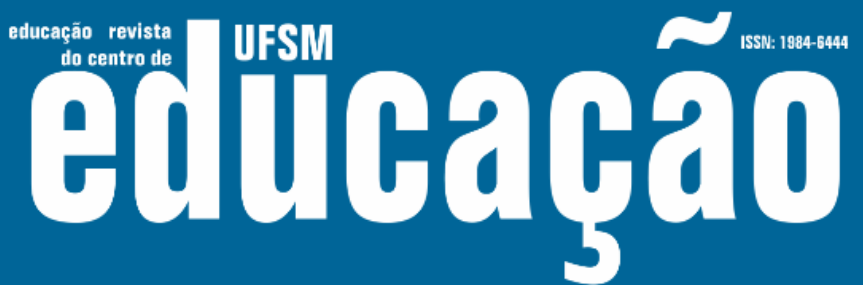

ISSN: 1984-6444 | http://dx.doi.org/10.5902/1984644435065

consciência' interno preexistente; se trata de um processo no qual este plano interior vai se formando."

O movimento dessa interiorização ocorre essencialmente mediado pelos outros das relações do sujeito, nunca é um processo absolutamente individual, nem diretamente externo. A pessoa nunca é uma cópia do ser social. Portanto, a relação interpsicológica se mostra como um momento no qual um indivíduo precisa do outro para a mediação dos sistemas de orientação psíquica em meio social, mas o indivíduo o faz criativamente, transformando os significados sociais em sentidos pessoais.

O educador, em consequência, ocupa lugar central no processo de internalização das formas do ser social, necessárias à constituição do poder no sujeito para agir sobre a sua própria condição. Isso não quer dizer que aquele deva ser modelo, mas produzir intencionalmente ações de cooperação no processo de significação e formação do sentido pessoal.

\section{Considerações finais}

A título de finalização, é necessário ressaltar que, porque o mundo oferece resistência às ações, isso não constitui a causa do sofrimento. Essa mesma resistência que forma a unidade contraditória da ação, do movimento do homem, é sua, também, constituinte. O sofrimento advém da impossibilidade de romper a resistência, de pô-la em movimento. Nesse sentido, não somente os objetos com suas características físicas oferecem resistência, mas também as relações com outras pessoas, a compreensão da realidade social, o domínio das ideias, dos sentimentos e do pensamento. É aqui que o cuidado encontra lugar no trabalho do educador como agente transformador do ser social do sujeito do processo educativo, da sua personalidade.

A educação como processo de cuidado à pessoa, à personalidade aqui proposta, toma as relações sociais de poder e dominação no processo educativo como eixo do processo de significação. Poder e domínio das relações aparecem como lócus do desenvolvimento do sofrimento psicológico e da produção de modos particulares da sua expressão, que são crônicos ou reiterativos das necessidades 


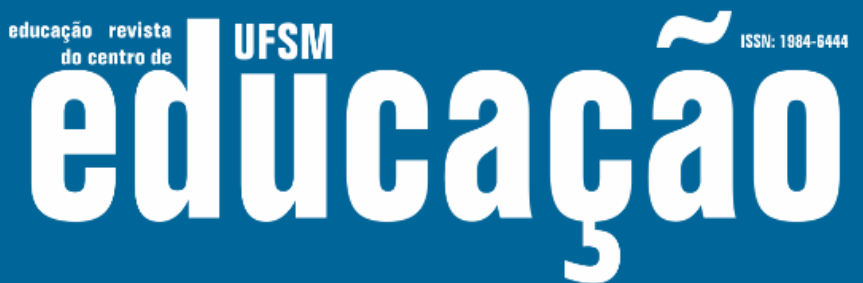

ISSN: 1984-6444 | http://dx.doi.org/10.5902/1984644435065

pessoais de desenvolvimento. Precisam também, ocupar o lugar do cuidado e desenvolvimento.

Finalizamos, então, considerando que o processo educativo que cria contradições que estão necessariamente ligadas à aquisição das formas de ser cultural, que inicialmente não existem no sistema psicológico da criança, precisa orientar-se para o ensino do uso dos instrumentos materiais e ideacionais da cultura para o domínio e resolução das problemáticas que a criança enfrenta a cada momento da sua vida. A possibilidade de dominar os meios da superação das contradições é o caminho para a superação do sofrimento psicológico e desenvolvimento harmônico da personalidade no processo educativo.

\section{Referências}

MATUSOV, Eugene; MIYAZAKI, Kiyotaka. Dialogue on Dialogic Pedagogy: An International Online Journal | Vol. 2, 2014. Disponível em: https://dpj.pitt.edu/ojs/index.php/dpj1/article/view/121. Acesso em: 10 jan. 2018.

LEONTIEV, Alexis Nikolaevich. O desenvolvimento do psiquismo. Tradução de Newton Duarte. Lisboa: Livros Horizonte, 1978. 350p.

LEONTIEV, Alexis Nikolaevich. A. N. Actividad, conciencia y personalidad. Buenos Aires: Ediciones del Hombre. 1978a. 182p.

LURIA, Alexander Romanovich. Vigotskii. In: VIGOTSKII, L. S., LURIA, A. R., LEONTIEV, A. N. Linguagem, desenvolvimento e aprendizagem. Tradução de Maria Penha. 6 ed. São Paulo: Ícone, 1998. Cap. 1 p. 21-37.

MARX, Karl. Manuscritos econômico-filosóficos. Tradução de Jesus Raniere. São Paulo: Boitempo Editorial, 2004. 175p.

MARX, K.; ENGELS, F. A Ideologia Alemã. Traduzido por José Carlos Bruni e Marco Aurélio Nogueira, Barcelona: Grijalbo, 1977.

MÉSZÁROS, István. Educação para além do capital. Tradução de Isa Tavares. São Paulo: Boitempo, 2005. 125p.

PINO, Angel. Violência, Educação e Sociedade: um olhar sobre o Brasil contemporâneo. Educação e Sociedade. Campinas, vol. 28, n. 100 - Especial, p. 763-785, out. 2007. 


\section{Aitlpap̧ão}

ISSN: 1984-6444 | http://dx.doi.org/10.5902/1984644435065

SPOSITO, Marilia. Pontes. Um breve balanço da pesquisa sobre violência escolar no Brasil. Educação e Pesquisa. São Paulo, v. 27, n. 1, p. 87-103. Jan./jun. 2001.

SULLIVAN, Paul. Dialogue on Dialogue on Dialogic Pedagogy. An International Online Journal, v. 2, 2014. Disponível em: https://dpj.pitt.edu/ojs/index.php/dpj1/arti cle/view/121.Acesso em: 10 jan. 2018.

VYGOTSKI, Liev Semyonovich. Obras Escogidas IV. Madrid: Visor. 1996. 427p.

VYGOTSKI, Liev Semyonovich. Obras Escogidas III. Madrid: Visor. 2000. 383p.

VYGOTSKI, Liev Semyonovich. Obras Escogidas II. 2ed. Madrid: Visor. 2001a. 484p.

VIGOTSKI, Liev Semyonovich. A construção do pensamento e da linguagem. 1‥ed. São Paulo: Martins Fontes. 2001. 496p.

VIGOTSKI, Liev Semyonovich. Psicologia pedagógica. Tradução de Paulo Bezerra. 2.ed. São Paulo: Martins Fontes. 2001b. 561p.

WILDE, Lawrence. Logic: Dialectic and contradiction. In: WILDE, L. The Cambridge Companion to Marx. Cambridge: Cambridge University Press. 1999. Cap. 11, p. 275295, 357p.

ILYENKOV, Evald Vasilievich. Psychology. In: Journal of Russian and East European Psychology, vol. 48, no. 4, Spring, 2010 p. 9-49.

\section{Correspondência}

Armando Marino Filho - Universidade Federal de Mato Grosso do Sul - Campus II Av. Capitão Olinto Mancini, 1662, Jardim Primaveril., CEP 79600-080 - Três Lagoas, Mato Grosso do Sul, Brasil.

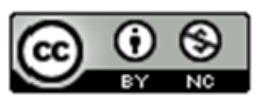

This work is licensed under a Creative Commons Attribution-NonCommercial 4.0 International (CC BY-NC 4.0) 